\title{
On the search of efficient uses for glycerine: steam gasification
}

\author{
J. F. González ${ }^{1}$, G. Engo ${ }^{1}$, S. Román ${ }^{1}$, M. C. Rayo ${ }^{1}$, F. J. Masa ${ }^{1}$, J. M. Encinar ${ }^{2}$ \\ ${ }^{1}$ Departament of Applied Physics, ${ }^{2}$ Department of Chemical Engineering and Physical Chemistry, \\ University of Extremadura, Avda. Elvas s/n, 06006, Badajoz \\ e-mail: jfelixgg@unex.es
}

\begin{abstract}
This work deals with the steam gasification of the glycerine generated during the biodiesel manufacture in an industrial plant. Glycerine (diluted in water) was gasified with the aim of producing an hydrogen-rich gas, making a systematic investigation on the influence of the gasification temperature in the range $600-1000{ }^{\circ} \mathrm{C}$. It was found that the change in this parameter influences the composition of the gas generated during gasification, driving the process towards a higher hydrogen production as the temperature gets greater. On the other hand, if the aim is to produce a gas with a higher energy content, a lower temperature would be more favourable.
\end{abstract}

\section{Key words}

Glycerine, gasification, hydrogen, biodiesel

\section{Introduction}

Biodiesel is one of the alternative fuels used to meet the current energy requirements. Apart from the null net $\mathrm{CO}_{2}$ emissions it provides, it can be used for automotive applications, which makes it more interesting than other alternative energy sources.

During biodiesel production by means of transesterification of oils and animal fats, glycerine is formed as by-product in a ratio of approximately $10 \%$ (weight referred to biodiesel production). This quantity of glycerin is huge if we consider that biodiesel production is increasing to get a more significant role in the next energy scheme. As more biodiesel is produced, the price of glycerin decreases and the need of searching new ways to provide an added value to this product becomes an imperative. With increased production of biodiesel, a glut of glycerol $\left(\mathrm{C}_{3} \mathrm{H}_{8} \mathrm{O}_{3}\right)$ is expected in the world market, and therefore it is essential to find useful applications for glycerol. Currently, glycerol is used in many applications including personal care, food, oral care, tobacco, polymer and pharmaceutical applications. However, explosive growth of biodiesel industry has created a glut in glycerol that has demeaned the market value of this commodity. Therefore, finding alternative uses for glycerol is important. One possibility is using glycerol as a source for producing hydrogen.

In this line, some studies regarding the steam gasification of glycerine for the production of hydrogen, syn gas and medium heating value gas have been made [1-9]. These works showed that glycerin steam gasification is a very complex process in which concurrent, consecutive, dehydration and cracking reactions all compete to transform glycerin into $\mathrm{H}_{2}$, syn gas and char [1]. Theoretically, one mole of glycerin would give four moles of $\mathrm{H}_{2}$. However, up to now, the most interesting results found in the bibliography show conversions lower than $60 \%$ [1], which is already very attractive.

Although this field is a hot topic for research, given the many advantages it can offer once the process has been optimized, the knowledge on the mechanisms governing glycerine degradation reactions is very scarce.

With these premises, this work studied the steam gasification of glycerine (diluted in water) with the aim of producing an hydrogen-rich gas, making a systematic investigation on the influence of the temperature (600, $700,800,900$ and $\left.1000{ }^{\circ} \mathrm{C}\right)$. The water-to-glycerol feed ratio and steam flow rate were $12: 1$ and $2.5 \mathrm{~cm}^{3} \mathrm{~min}^{-1}$, respectively.

\section{Experimental}

Glycerine was provided by the Biodiesel manufacture plant of Bioenergética Extremeña, located in Valdetorres (Extremadura, Spain).

The runs were performed under continuous regime, using a two stage gasification system as the one shown in Figure 1.

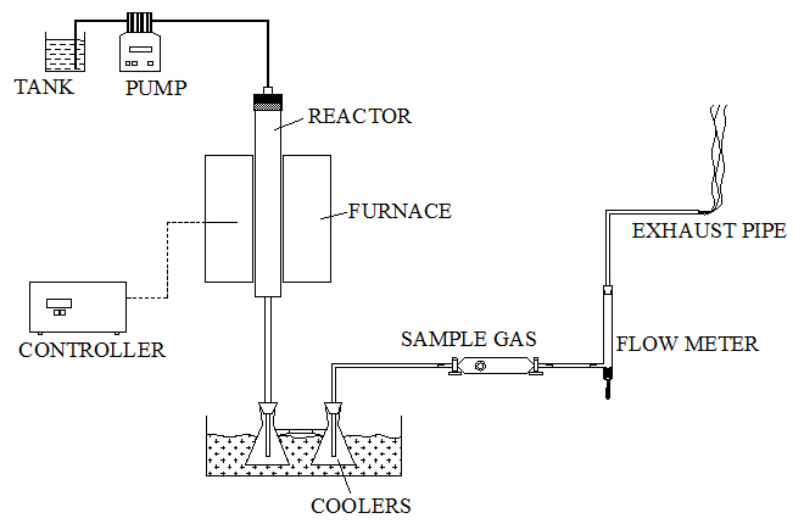

Figure 1. Experimental set-up

It consists basically on a stainless steel tubular reactor (inner diameter of $3.5 \mathrm{~cm}$ and length of $70 \mathrm{~cm}$ ) where the glycerine gasification processes with steam takes place. A peristaltic bomb introduces the adequate glycerine/water ratio directly into the reactor. The gas produced is then passed through a quenching system (glass recipients covered by ice), where the condensable liquids are collected. Once the steady regime has been 
reached, a gas sample is collected for further analysis. This operation is repeated several times to confirm the reliability of the results obtained. Therefore the data presented in this work is an average value.

The composition of the gas produced; mainly $\mathrm{H}_{2}, \mathrm{CO}$, $\mathrm{CO}_{2}$ and $\mathrm{CH}_{4}$, was analysed by a 4000 HRGC KONIK gas chromatograph provided with two thermal conductivity detectors, connected to two columns: Porapack Q and Carboxen-1000 (15 ft length, 1/8 inch diameter).

\section{Results and discussion}

In this paper, the results obtained in the reforming process of glycerine with water vapour are discussed. The hydrogen or syngas production and energy power obtained per $\mathrm{kg}$ of glycerine are valorized.

This work is a part of a wider investigation in which tree experimental series have been performed, varying the water-to-glycerol feed ratio, WGFR in the range $2: 1,6: 1$, 9:1 and 12:1. In each series the temperature and flow rate has been varied in the ranges $600-1000{ }^{\circ} \mathrm{C}$ and 0.5 a 3 $\mathrm{cm}^{3} \min ^{-1}$, respectively.

In this case, the influence of the temperature on the main parameters of the reaction thus as quality and energetic value of gas, moles of gas $/ \mathrm{min}$, moles of each gas $/ \mathrm{mol}$ of glycerine, molar fractions of gas compounds, lower heating value of gas (in $\mathrm{kJ} / \mathrm{Nm}^{3}$ ) and energetic power generated (in $\mathrm{kW}$ ) are analyzed. The results obtained for the experimental series carried out at different temperatures with a WGFR of 12:1 and a flow rate of 2.5 $\mathrm{cm}^{3} \min ^{-1}$ are discussed here.

The reforming of glycerine with vapour produces $\mathrm{H}_{2}$, $\mathrm{CH}_{4}, \mathrm{CO}, \mathrm{CO}_{2}$, and $\mathrm{C}$, together with non-reacted water and glycerol. Only the discussion of these compounds will be analysed because they are the primary products formed in the reforming of glycerine with vapor $[5,6]$.

First, it is necessary to study the global reaction of vapor reforming of glycerine, which is:

$\mathrm{C}_{3} \mathrm{H}_{8} \mathrm{O}_{3}(\mathrm{~g})+3 \mathrm{H}_{2} \mathrm{O}(\mathrm{g}) \leftrightarrow 7 \mathrm{H}_{2}(\mathrm{~g})+3 \mathrm{CO}_{2}(\mathrm{~g})$

$\Delta \mathrm{H}=225.29 \mathrm{~kJ} / \mathrm{mol}$

Thermodynamically, the reforming reaction is an endothermic reaction and the equilibrium constant is high enough to convert glycerine completely at appropriate temperatures $\left(227^{\circ} \mathrm{C}\right)$ [7]. Therefore, it is viable to reform glycerine for hydrogen production from a liquid phase at relatively low temperature. However, the reforming in aqueous phase of polyalcohols is very complex and many secondary reactions are possible, including parallel and consecutive [8].

The glycerol reforming for hydrogen production involves complex reactions. As a result, various intermediary byproducts are formed and finish in the product stream affecting the final purity of hydrogen produced. Moreover, the hydrogen yield depending of several variables of process, such as pressure, temperature, feeding caudal and water-to-glycerol feed ratio [8, 9].

Figure 2 shows the temperature influence on the moles of each gas $/ \mathrm{min}$ generated for a feeding flow rate of $2.5 \mathrm{~cm}^{3}$ $\min ^{-1}$. One can be observe that increasing temperature produces a practically lineal increase of $\mathrm{H}_{2}$, a decrease of $\mathrm{CO}$, an increase of $\mathrm{CO}_{2}$ until $900{ }^{\circ} \mathrm{C}$ (decreasing after). The same tendency is observed for $\mathrm{CH}_{4}$ although less accused than in the case of $\mathrm{CO}_{2}$.

Also, in Figures 2 and 3 an increase of the mol number of $\mathrm{H}_{2}$ obtained per each mol of glycerine can be appreciated (although it is far from the 7 moles of $\mathrm{H}_{2}$ per mol of glycerine that is the maximum production of this gas according to the equation 1) and the molar fraction of $\mathrm{H}_{2}$ increases as the reaction temperature increases. Also an increase of $\mathrm{CO}_{2}$ and $\mathrm{CH}_{4}$ up to $900{ }^{\circ} \mathrm{C}$ and a decrease of $\mathrm{CO}$ can be appreciated as the temperature increases. Adhikari et al., (2007b) have observed an increase in the $\mathrm{CO}$ and $\mathrm{H}_{2}$ production with the increase of temperature until $1000 \mathrm{~K}$, while they found a decrease of the $\mathrm{CH}_{4}$ production. Moreover, they obtained a maximum in the $\mathrm{CO}_{2}$ production at $800-850 \mathrm{~K}$ for the different water-toglycerol feed ratios tested by those authors. This effect is somehow also observed in this work, (respect to $\mathrm{H}_{2}$ and $\mathrm{CO}_{2}$ produced), but the maximum in the $\mathrm{CO}_{2}$ production is observed at $900{ }^{\circ} \mathrm{C}$. In the case of $\mathrm{CH}_{4}$ production, a maximum is also observed at $900{ }^{\circ} \mathrm{C}$, therefore the participation of secondary reactions such as:

Water gas shift reaction:

$\mathrm{CO}(\mathrm{g})+\mathrm{H}_{2} \mathrm{O}(\mathrm{g}) \leftrightarrow \mathrm{H}_{2}(\mathrm{~g})+\mathrm{CO}_{2}(\mathrm{~g})$

$\Delta \mathrm{H}=-40.9 \mathrm{~kJ} / \mathrm{mol}$

Steam reforming reactions:

$\mathrm{CH}_{4}(\mathrm{~g})+2 \mathrm{H}_{2} \mathrm{O}(\mathrm{g}) \leftrightarrow 4 \mathrm{H}_{2}(\mathrm{~g})+\mathrm{CO}_{2}(\mathrm{~g})$

$\Delta \mathrm{H}=165.0 \mathrm{~kJ} / \mathrm{mol}$

$\mathrm{CH}_{4}(\mathrm{~g})+\mathrm{H}_{2} \mathrm{O}(\mathrm{g}) \leftrightarrow 3 \mathrm{H}_{2}(\mathrm{~g})+\mathrm{CO}(\mathrm{g})$

$\Delta \mathrm{H}=206.3 \mathrm{~kJ} / \mathrm{mol}$

These equilibria can explain the composition of final gas obtained. The reactions 3 and 4 must be favoured with the temperature because they are endothermic reactions. However, the reaction (2) is slightly exothermic. The justification of the final gas composition can be analyzed, evaluating the effects of the ratios showed in Table 1.

In this series, the ratio $\mathrm{CO} / \mathrm{CH}_{4}$ decreases from 4.94 to 1.24 and the ratio $\mathrm{H}_{2} / \mathrm{CO}$ increases strongly as one can see in Table 1, consequently, the reaction (4) participates scantily in the composition of the generated gas. The reaction water gas shift must participate in the final gas composition, because this reaction must be favoured with the increase of the reaction temperature. This circumstance can be justified, if one observes the reduction of the ratios $\mathrm{CO} / \mathrm{CO}_{2}$ and $\mathrm{H}_{2} / \mathrm{CO}_{2}$ (in this case until $900{ }^{\circ} \mathrm{C}$ ) and the strong increase experimented by the ratio $\mathrm{H}_{2} / \mathrm{CO}$. Logically, the final gas composition can be also influenced by the participation of the reforming of glycerine (equation 1), which is endothermic. 
The reforming reactions must be favoured because of the strong increase of the ratio $\mathrm{H}_{2} / \mathrm{CH}_{4}$ (see Table 1). In Figure 4 (where the molar fractions of gases versus temperature is plotted), one can see an increase and decrease of the molar fractions of $\mathrm{H}_{2}$ and $\mathrm{CH}_{4}$, respectively, as the reaction temperature is increased. Also, a decrease of molar fraction of $\mathrm{CO}$ with increasing temperature is observed. The molar fraction of $\mathrm{CO}$ reaches a maximum at a temperature of $900{ }^{\circ} \mathrm{C}$. An hydrogen-rich gas with a molar fraction of $61.3 \%$ was obtained for a temperature of $1000{ }^{\circ} \mathrm{C}$.

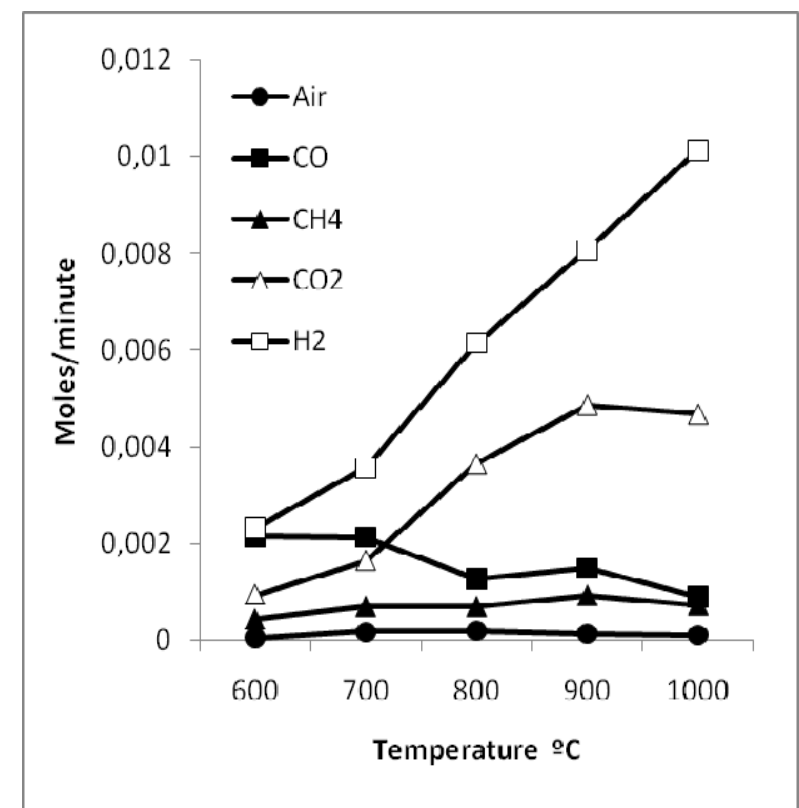

Figure 2. Influence of the temperature on the generated moles de gases per minute $\left(\mathrm{WFGR}=12: 1, \mathrm{Q}=2.5 \mathrm{~cm}^{3} \mathrm{~min}^{-1}\right)$.

Figure 1 shows the number of moles of each gas per volume unit of glycerine (mole $\mathrm{mL}^{-1}$ ) for the different runs made.

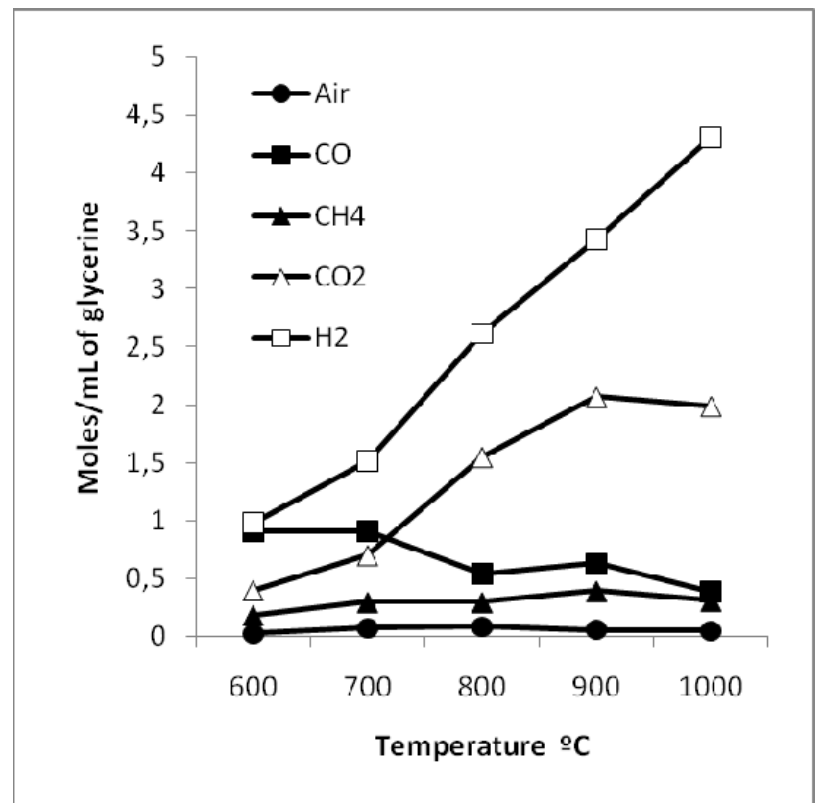

Figure 3. Influence of temperature on the moles of gases per $\mathrm{cm}^{3}$ of glycerine $\left(W F G R=12: 1, Q=2.5 \mathrm{~cm}^{3} \mathrm{~min}^{-1}\right)$.

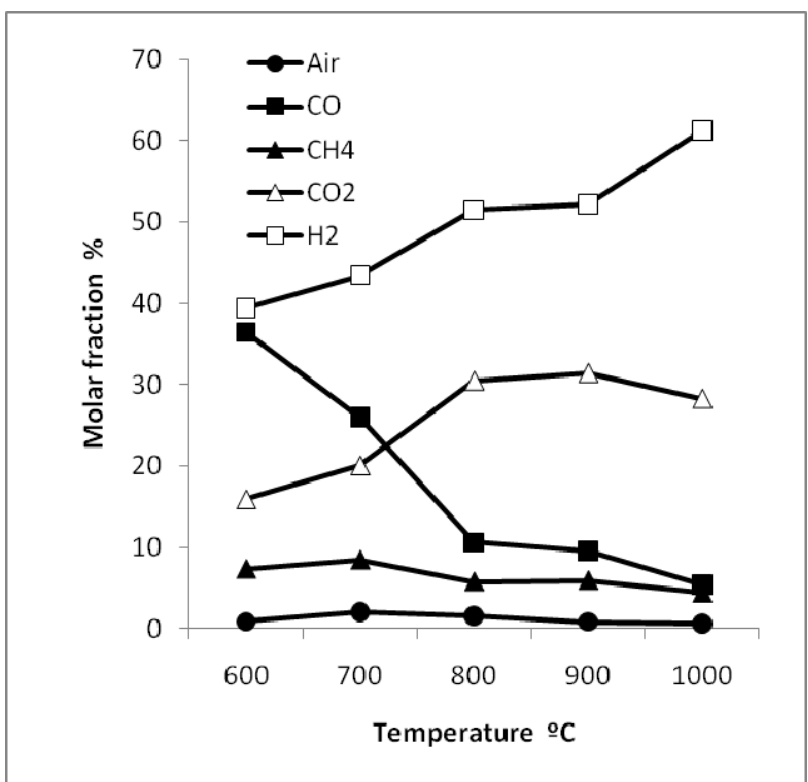

Fig. 4. Influence of temperature on the molar fractions of generated gases $\left(\mathrm{WFGR}=12: 1, \mathrm{Q}=2.5 \mathrm{~cm}^{3} \mathrm{~min}^{-1}\right)$.

Table 1. Influence of temperature on the Ratios $\mathrm{H}_{2} / \mathrm{CO}, \mathrm{H}_{2} / \mathrm{CH}_{4}$, $\mathrm{CO} / \mathrm{CO}_{2}, \mathrm{CH}_{4} / \mathrm{CO}_{2}$ e $\mathrm{H}_{2} / \mathrm{CO}_{2}\left(W F G R=12: 1, Q=2.5 \mathrm{~cm}^{3} \mathrm{~min}^{-1}\right)$.

\begin{tabular}{|c|c|c|c|c|c|}
\hline $\mathrm{T},{ }^{\circ} \mathrm{C}$ & $\begin{array}{c}\text { Ratio } \\
\mathrm{H}_{2} / \mathrm{CO}\end{array}$ & $\begin{array}{c}\text { Ratio } \\
\mathrm{H}_{2} / \mathrm{CH}_{4}\end{array}$ & $\begin{array}{c}\text { Ratio } \\
\mathrm{CO} / \mathrm{CO}_{2}\end{array}$ & $\begin{array}{c}\text { Ratio } \\
\mathrm{CH}_{4} / \mathrm{CO}_{2}\end{array}$ & $\begin{array}{c}\text { Ratio } \\
\mathrm{H}_{2} / \mathrm{CO}_{2}\end{array}$ \\
\hline 600 & 1.08 & 5.35 & 2.29 & 0.46 & 2.48 \\
\hline 700 & 1.67 & 5.11 & 1.29 & 0.42 & 2.16 \\
\hline 800 & 4.84 & 8.85 & 0.35 & 0.19 & 1.68 \\
\hline 900 & 5.45 & 8.73 & 0.30 & 0.18 & 1.66 \\
\hline 1000 & 11.28 & 13.96 & 0.19 & 0.15 & 2.16 \\
\hline
\end{tabular}

The results obtained allowed concluding that the use of different water/glycerine ratios influenced the composition of the gas obtained: a more diluted glycerine/water ratio gives rise to a higher hydrogen fraction, in coherence with other studies [1].

On the other hand, using the molar composition $\left(\mathrm{H}_{2}, \mathrm{CO}\right.$, $\mathrm{CO}_{2}, \mathrm{CH}_{4}$ and air) of the gases generated, the low calorific value has been calculated. These results are collected in Table 2.

Table 2. Lower Heating Value of the gases generated

\begin{tabular}{cc}
\hline $\mathbf{T},{ }^{\circ} \mathbf{C}$ & $\mathbf{L H V}\left(\mathbf{k J} / \mathbf{N m}^{3}\right)$ \\
\hline 600 & 11488.5 \\
700 & 11000.8 \\
800 & 8959.9 \\
900 & 8956.1 \\
1000 & 8846.3 \\
\hline
\end{tabular}

From Table 2 it can be inferred that the use of higher temperatures is not interesting if the aim is to produce an energetic gas. The decrease in the heating value could be associated with the cracking of gases as $\mathrm{CH}_{4}$, as it has been suggested [3], and also due to the strong decrease observed in the $\mathrm{CO}$ content of final gas.

In Figure 5 the influence of temperature on the power generated (in W) is plotted. This parameter is strongly influenced by the gas flow rate generated. One can 
observe that the temperature increase produces a strong increase of the generated power. This result is interesting for the design of an industrial plant of glycerine reforming, because the power is increased one hundred percent with increasing temperature from 600 to $1000{ }^{\circ} \mathrm{C}$. However, the energy consumption would be higher as the temperature is increased. In this sense, the participation of a catalyst in the reaction medium could reduce the temperature and thus to diminish the energy consumption in the global process. We are studying the cited effect using catalysts derived of $\mathrm{Ni}$.

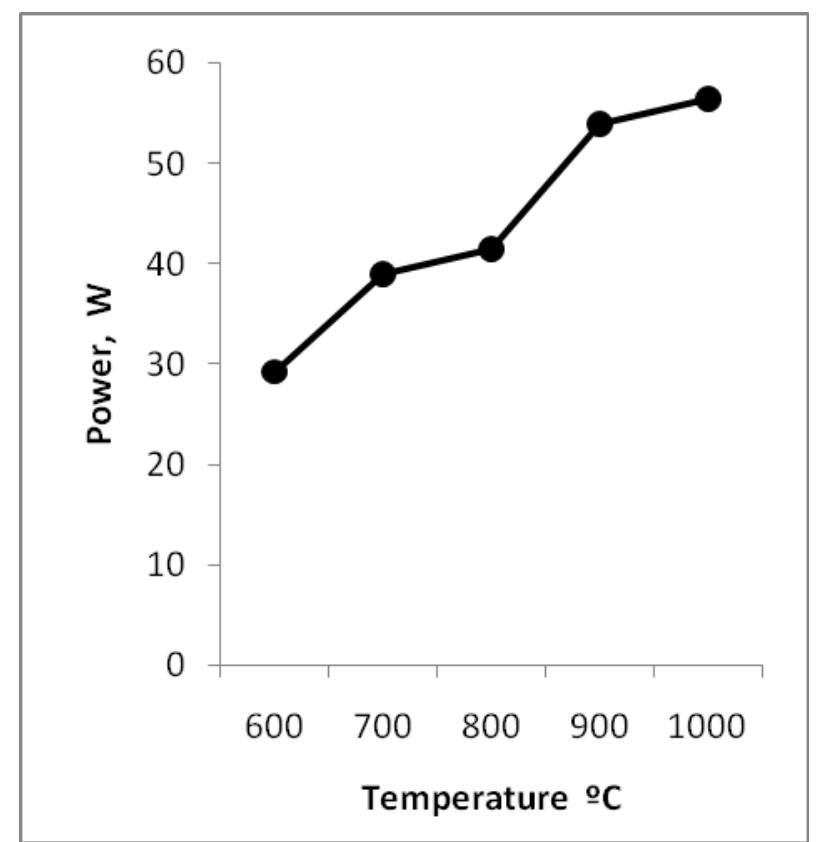

Figure 5. Influence of temperature on the generated power (WFGR $\left.=12: 1, \mathrm{Q}=2.5 \mathrm{~cm}^{3} \mathrm{~min}^{-1}\right)$.

\section{Conclusions}

Glycerine reforming at higher temperatures (temperatures in the range $600-1000{ }^{\circ} \mathrm{C}, \mathrm{WFGR}=12: 1, \mathrm{Q}=2.5 \mathrm{~cm}^{3}$ $\mathrm{min}^{-1}$ ) was investigated in this work with the aim of to produce an hydrogen-rich gas. A molar fraction of 61.3 $\%$ was obtained for a temperature of $1000{ }^{\circ} \mathrm{C}$. Increasing temperature gave place to a strong increase in $\mathrm{H}_{2}$ production and the decrease of $\mathrm{CO}$ and $\mathrm{CH}_{4}$ probably due the participation of secondary reactions that modify the final gas composition. From the results obtained, a decrease of lower heating value of gas was observed with the increase of temperature. However the power generated from the gas increased, which is interesting for the design of industrial plant.

\section{Acknowledgement}

The authors express their gratitude for the financial support through project PDT09A024.

M. C. Rayo thanks the Junta de Extremadura the predoctoral grant conceded.
[1] T. Valliyappan, N.N. Bakhshi, A.K. Dalai Pyrolysis of glycerol for the production of hydrogen or syn gas. Bioresource Technology 99 (2008) pp. 4476-4483.

[2] Y. S. Stein, M. J. Antal Jr., M. Jones Jr. A study of the gasphase pyrolysis of glycerol. Journal of Analytical and Applied Pyrolysis 4 (1983) 283-296.

[3] T. Valliyappan. Hydrogen or syn gas production from glycerol using pyrolysis and steam gasification processes. Doctoral Thesis. University of Saskatchewan, Canada (2004).

[4] T. Hirai, N-O. Ikenaga, T. Mayake, T. Suzuki. Production of hydrogen by steam reforming of glycerin on ruthenium catalyst. Energy Fuels 19, 2005, 1761-2.

[5] R.R. Soares, D.A. Simonetti, J.A. Dumesic. Glycerol as a source for fuels and chemicals by low-temperature catalytic processing. Angew Chem Int Ed 45, 2006, 39825 .

[6] N. Luo, X. Zhao, F. Cao, T. Xiao, D. Fang. Thermodynamic study on hydrogen generation from different glycerol reforming processes. Energy \& Fuels 21, 2007, 3505-12.

[7] N. Luo, X. Fu, F. Cao, T. Xiao, P.P. Edwards. Glycerol aqueous phase reforming for hydrogen generation over $\mathrm{Pt}$ catalyst - Effect of catalyst composition and reaction conditions. Fuel 87, 2008, 3483-3489.

[8] S. Adhikari, S. Fernando, A. Haryanto. A Comparative Thermodynamic and Experimental Analysis on Hydrogen Production by Steam Reforming of Glycerin. Energy \& Fuels 21, 2007a, 2306-2310.

[9] S. Adhikari, S. Fernando, S.R. Gwaltney, S.D. Filip-To, R.M. Bricka, P.H. Steele, A. Haryantoa. A thermodynamic analysis of hydrogen production by steam reforming of glycerol. International Journal of Hydrogen Energy 32, 2007b, 2875 - 2880 .

\section{References}

